\title{
ANALYTICAL PROBABILISTIC RESILIENCE ESTIMATION FOR BRIDGES UNDER NEAR-FAULT EARTHQUAKES
}

\author{
Yang Liu' ${ }^{1}$, Da-Gang Lu ${ }^{2}$, Fabrizio Paolacci ${ }^{3}$ \\ ${ }^{1}$ College of Architecture and Environment, Sichuan University \\ e-mail: liuyang6886@163.com \\ ${ }^{2}$ School of Civil Engineering, Harbin Institute of Technology \\ e-mail: ludagang@hit.edu.cn \\ ${ }^{3}$ Department of Engineering, Roma Tre University \\ e-mail: fabrizio.paolacci@uniroma3.it
}

\begin{abstract}
The seismic resilience is becoming an important indicator for the performance assessment of structures and infrastructure systems. This paper proposes a probabilistic approach based on seismic fragility analysis to assess the seismic resilience of steel-concrete composite bridges. By considering the structural and seismic uncertainties in different analysis steps of this approach, the sample generation process for probabilistic demand models is simplified, which largely reduced the computational burden. To deeper understand the seismic resilience and better describe the uncertainties, the estimation interval of the expected resilience is given, while the uncertainties are considered in fragility and propagated to the resilience. This approach is applied to a new typology of steel-concrete composite bridge endowed with concrete cross beams, which has been analyzed within the European Research Project SEQBRI. The results show that this probabilistic approach can largely speed up the process of seismic resilience assessment, while both the aleatory and epistemic uncertainties are considered. Meanwhile, the resilience of the bridge is assessed under both the near-fault and the far-field ground motions which aim to study the influence of near-fault earthquakes on the seismic resilience.
\end{abstract}

Keywords: Seismic resilience; seismic fragility; steel-concrete composite bridges; near-fault earthquakes.

ISSN:2623-3347 @ 2021 The Authors. Published by Eccomas Proceedia.

Peer-review under responsibility of the organizing committee of COMPDYN 2021. doi: $10.7712 / 120121.8726 .19090$ 


\section{INTRODUCTION}

The concept of seismic resilience has been fast developing in recent years, which plays an important role in performance assessment especially for infrastructure systems. The structural condition of bridges is one of the key aspects of the functionality of transportation networks, which must correspond to an acceptable resilience level to guarantee the efficient flow of people and services (Deco et al. 2013). However, the approach on seismic resilience assessment for bridges has not been yet adequately investigated, being in general difficult to be performed especially for near-fault earthquakes.

Deterministic approaches for seismic resilience evaluation have been developed in the past by many researches. Bruneau et al. (2003) proposed the preliminary framework of seismic resilience assessment. Xu et al. (2007), Frangopol and Bocchini (2011) were interested in the recovery scheduling optimization, while Cimellaro et al. (2010) developed the recovery functions based on empirical formulas. Further developments proposed a probabilistic treatment of the seismic resilience. For example, Deco et al. (2013) suggested a probabilistic approach for resilience prediction based on fragility analysis, while Karamlou and Bocchini (2015) assessed the accuracy of traditional fragility methods for resilience prediction.

The performance-based earthquake engineering (PBEE) approach has been broadly proposed to assess the seismic performance of structures and supporting decision-makers in disaster management. The probabilistic approach adopted by PBEE allows considering the intrinsic randomness related to earthquakes and structures. In this respect, a seminal work concerning the probabilistic seismic demand analysis (PSDA) was performed by Shome (1999), in which the uncertainty of the seismic demand was accounted for. Cornell et al. (2002) derived the demand fragility functions to combine the inherent uncertainties of seismic hazard and structural response. Deco and Frangopol (2013) proposed a method for resilience calculation of bridges in seismic prone-areas including structural uncertainties and variability in the restoration process and rehabilitation costs.

It is worth mentioning that the epistemic uncertainties, which derive mainly from the inadequacy of FE models, cannot be totally neglected (Ellingwood et al. 2009). However, in the previous analyzed works, the epistemic uncertainty for resilience analysis has not been correctly accounted for, which should instead be quantitatively calculated for improving the accuracy of probability models. Therefore, an advancement towards this direction appears necessary.

According to the above-depicted framework, this paper presents a probabilistic approach to estimate the seismic resilience for bridges. For this purpose, analytical seismic fragility functions are used, accounting for both aleatory and epistemic uncertainty associated with earthquake event, structural response and expected damage (Lu et al. 2014). The point and interval estimation methods are firstly used for the expected recovery curves, which allow to easily estimate the seismic resilience and help decision-makers in predicting the seismic performance of bridges. The procedure is then applied to a short-span steel-concrete composite (SCC) bridge which has been analyzed within the Project SEQBRI. In order to estimate the seismic performance of bridges under an extreme event, the effect of near-fault earthquakes is considered. Finally, simplified seismic fragility analysis and seismic resilience estimation of the case study are performed.

\section{ASSESSMENT METHODOLOGY}

In this section, a simplified method to assess the seismic resilience of bridges is presented, which consists of four steps as illustrated in Fig. 1: 

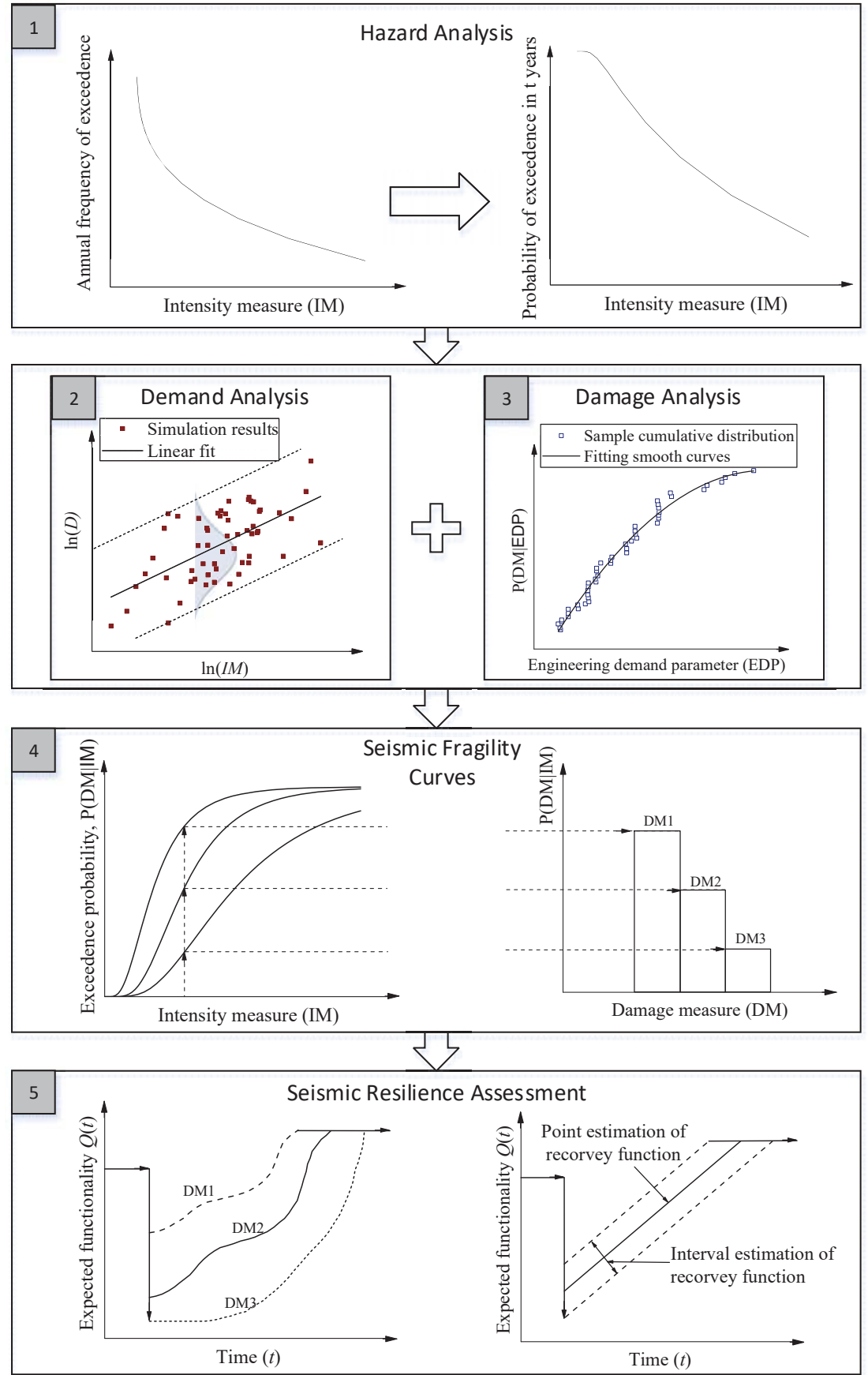

Fig. 1 Analysis stages of assessment methodology

1. Seismic hazard analysis. The classical Probabilistic Seismic Hazard Analysis (PSHA) is here in adopted, which provides the mean annual frequency (MAF) of exceedance of a selected intensity measure (IM) for all possible sources generating an earthquake (Cornell 1968);

2. Seismic demand analysis. Among different nonlinear demand estimation methods for the PSDA, the Cloud Analysis (CA) certainly is the commonly used. This method consists in 
generating cloud of Engineering Demand Parameter (EDP) values for a set of earthquake ground motion records characterized by a hazard-consistent IM. Basic and improved versions of CA have been proposed to account for the inherent randomness of the seismic action in the form of record-to-record variability only or also the epistemic uncertainty, related to the modelling (Bazzurro 1998; Cornell et al. 2002; Ellingwood et al. 2009). In this work only the basic version has been implemented to evaluate the probability of exceedance (POE) of a given demand level.

3. Damage Analysis. The damage analysis aims at predicting the structural damage at component level as function of demand parameters. Any damage level, usually expressed in terms of Damage Measures (DM), presents variability with EDP due to the uncertainty of material properties and structural response history (Gardoni et al 2002).

4. Fragility Analysis. In this step, the POE of a given DM conditioned to a selected IM is determined by adopting an analytical approach. By assuming a lognormal distribution, a closed- form formulation of demand and capacity fragility curves is proposed, which accounts for epistemic uncertainty as well.

5. Resilience estimation. This is the last step that consists in the seismic resilience assessment for different structural damage level caused by the earthquake event, considering the uncertainty associated with the restoration process.

This paper focuses on the previous steps and proposes a methodology based on numerical simulation, which is described in the following sub-sections.

\subsection{Probabilistic seismic demand models (PSDA)}

The purpose of PSDA is to establish a probabilistic relationship between the selected EDP and IM (Tondini and Stojadinovic 2012).

It is assumed that the seismic demand $D$ follows a lognormal distribution (Cornell et al. 2002). The probability of exceeding the demand level $d$ conditioned on $I M=x$ can be expressed as:

$$
P[D \geq d \mid I M=x]=1-\Phi\left[\frac{\ln (d)-\ln \left(m_{D}\right)}{\beta_{D \mid I M}}\right]=1-\Phi\left[\frac{\ln \left(\frac{d}{m_{D}}\right)}{\beta_{D \mid I M}}\right]
$$

where, $m_{D}$ is the median of the demand parameter EDP, $\beta_{D \mid M}$ is the dispersion of the demand about its median value conditioned to $I M$, and $\Phi(\cdot)$ is the standard normal cumulative distribution function. Additionally, $m_{D}$ can be assumed linear in the log-log space (Cornell et al. 2002). Consequently, the probabilistic seismic demand model (PSDM) can be expressed as

$$
\ln \left(m_{D}\right)=a+b \ln (I M)
$$

in which, $a$ and $b$ are regression parameters, which could be assessed by a linear regression analysis on the logarithmic maximum response versus $\ln I M$. Accordingly, the logarithmic standard deviation could be estimated by the following formula:

$$
\beta_{D \mid I M}=\sqrt{\frac{\sum_{i=1}^{N}\left[\ln \left(d_{i}\right)-\ln \left(m_{D}\right)\right]^{2}}{N-2}}
$$

Previous studies on bridges clearly demonstrated that the uncertainty from earthquakes events is much bigger than that of structures (Wen et al. 2003; Padgett and Des-Roches 2007). For this reason, in the following only the randomness due to the earthquake is considered by selecting suites of ground motions and generating samples of EDPs. For this approach simplified, the computational burden is reduced several times in time -history analysis. 


\subsection{Seismic fragility functions}

The seismic fragility represents the probability of occurrence or exceeding specified levels of damage in the considered range of IMs. This can also be expressed in terms of probability of the seismic demand (D) exceeding the seismic capacity (C) at the component or system level, conditioned on $\mathrm{IM}=\mathrm{x}$ :

$$
F_{R}(x)=P(D M \mid I M=x)=P(D>C \mid I M=x)
$$

Assuming that the capacity (C) obeys lognormal distribution, using Equations (1) and (2), the fragility function can be further derived as:

$$
F_{R}(x)=\Phi\left[\frac{\ln \left(m_{D \mid I M}\right)-\ln \left(m_{C}\right)}{\sqrt{\beta_{D \mid I M=x}^{2}+\beta_{C}^{2}}}\right]=\Phi\left[\frac{\ln \left(a I M^{b}\right)-\ln \left(m_{C}\right)}{\sqrt{\beta_{D \mid I M=x}^{2}+\beta_{C}^{2}}}\right]
$$

where, $\mu_{\mathrm{C}}$ and $\beta_{\mathrm{C}}$ are, respectively, the median and the dispersion of the capacity. These parameters can be evaluated performing the probabilistic damage analysis adopting either experimental or numerical approaches (Melchers 1999). The fragility function can be further derived as:

$$
F_{R}(x)=\Phi\left[\frac{\ln \left(a I M^{b}\right)-\ln \left(m_{C}\right)}{\sqrt{\beta_{D \mid I M=x}^{2}+\beta_{C}^{2}}}\right]=\Phi\left[\frac{\ln \left(m_{D \mid I M}\right)-\ln \left(m_{C}\right)}{\sqrt{\beta_{D \mid I M=x}^{2}+\beta_{C}^{2}}}\right]=\Phi\left[\frac{\ln \left(x / m_{R}\right)}{\beta_{R}}\right]
$$

where, $\mu_{R}$ and $\beta_{R}$ are, are, respectively, the median and the dispersion of the fragility, obviously, the parameters of the fragility can be re-formulated as(Lu et al. 2014):

$$
\begin{gathered}
m_{R}=\left(\frac{m_{C}}{a}\right)^{\frac{1}{b}} \\
\beta_{R}=\left(\frac{1}{b}\right) \sqrt{\beta_{D \mid I M=x}^{2}+\beta_{C}^{2}}
\end{gathered}
$$

\subsection{Probabilistic seismic resilience assessment}

In the field of civil engineering, the seismic resilience is defined as the ability of structures to contain the effects of a seismic event adopting effective measures to recover functionality after disasters and mitigate the effects of the future seismic risk (Bruneau et al. 2003). However, resilience is a multifaceted concept, which covers too broadly social and technical aspects to be defined with a single analytical function. In the present paper the following definition of resilience index $\mathrm{R}$ is adopted (Deco et al. 2013):

$$
R=\frac{\int_{t_{0}}^{t_{0}+t_{h}} Q(t) d t}{t_{h}}
$$

where $\mathrm{Q}(\mathrm{t})$ is the functionality of the structure, which depends on time $\mathrm{t}$, t0 is the occurrence time of the earthquake, and th is the investigated time horizon. Based on the total probability theorem, the estimation of structural functionality at any specific time $t$ after an earthquake can be calculated. Assuming a limited range of earthquake intensity, the expected functionality - ("Q" ) ("t" ) can be computed as following (Karamlou et al. 2015),

$$
\bar{Q}(t)=\sum_{i}^{n_{I M}} P(I M=i) \sum_{j}^{n_{D S}} P(D S=j \mid I M=i) Q_{j}(t)
$$

where, "P $(I M=i) "$ is the probability of occurrence of the earthquake while the intensity IM=i, computed by using PSHA for the bridge location site (FEMA445). The second item of the right hand of the equation, "P(DS = j|IM=i)," is the vulnerability expressed as the probability of being in the damage state $\mathrm{j}$ conditioned on "IM $=\mathrm{i}$ ". Qj(t) is the time-variant functionality of the structure in the case of initial damage state $\mathrm{j}$. Being different from buildings, the functionality of highway facilities (e.g., bridges) is usually defined as the carrying capacity of traffic under normal situations (ATC13).

\subsection{Quantification of uncertainties, point estimation and interval estimation}

In the field of civil engineering, the seismic resilience is defined as the ability of structures to con 
In order to develop reliable probabilistic models the various sources of uncertainties need to be quantified. Two broad types of uncertainties in probability models have to be dealt with: aleatory uncertainties and epistemic uncertainties. The formers are involved in the modeling and evaluation of low-probability, high-consequence events in nature, which are caused by the inherent variability and randomness in nature, and cannot be influenced by the observation. The epistemic uncertainties arise from our limited knowledge, imperfect modeling and simplifications (Ellingwood and Kinali 2009).

As shown in Equation (6), the two probabilistic models of demand and capacity can be integrated into a unitary probabilistic model of the fragility. Alternatively, the fragility model can be separated into a probabilistic demand and a capacity model.

Following the first approach, the uncertainty of the demand and the capacity are considered separately. Referring to the probabilistic seismic demand analysis (PSDA), the dispersion $\square \mathrm{D} \mid \mathrm{IM}$ represents the aleatory uncertainty raised from the randomness of the earthquake records input. That can be directly calculated in the PSDA. The epistemic uncertainty of the demand is instead not included in this model. This approach has been justified by Karamlou and Bocchini (2015) that have evaluated the epistemic uncertainty arising from the different assumptions used to build the probabilistic seismic demand models (PSDM). The effect of this uncertainty on the fragility is limited, whose influence range is smaller than $10 \%$. For this reason, in the following only the aleatory uncertainty $\square \mathrm{D} \mid \mathrm{IM}$ will be accounted for.

In the probabilistic capacity analysis, the capacity dispersion $\square \mathrm{C}$ generally contains two components of uncertainty (Wen et al. 2003), which is defined as:

$$
\beta_{C}=\sqrt{\beta_{C R}^{2}+\beta_{C U}^{2}}
$$

where the dispersion $\square \mathrm{CR}$ is the aleatory uncertainty arising from the randomness of the structural capacity, which can be assessed based on some experimental studies. The dispersion $\square \mathrm{CU}$ presents the epistemic uncertainty of capacity, which depends on the effects of the different sample sizes selection in probabilistic capacity seismic analysis (Ellingwood 2001; Ellingwood and Kinali 2009). The substitution of Equation (11) into Equation (8) leads to the point estimation of the fragility function considering the epistemic uncertainty:

$$
F_{R}(x)=\phi\left[\frac{\ln \left(x / m_{R}\right)}{\beta_{R}}\right]=\phi\left[\frac{\ln \left(a x^{b}\right)-\ln \left(m_{C}\right)}{\sqrt{\beta_{D \mid I M=x}^{2}+\beta_{C U}^{2}+\beta_{C R}^{2}}}\right]
$$

where the epistemic uncertainty of the fragility is presented by the dispersion $\square \mathrm{CU}$ of the capacity. In the second approach, the epistemic uncertainty in the fragility model is assumed unitary, which can be directly considered as the epistemic uncertainty of the median $\mathrm{mR}$ of the fragility curve (Eq. (6)). Therefore, the median of the fragility can be expressed as

$$
M_{R}=\varepsilon m_{R}
$$

in which the $\varepsilon$ is the random error of the median value.

It is assumed that the median of the fragility follows the lognormal distribution, whose median and dispersion are mR and $\square$ RU (Ellingwood and Kinali 2009; Lu et al. 2014). According to the definition of the confidence level $\mathrm{C}$, we have:

$$
\Phi\left[\frac{\ln \left(m_{R, \alpha} / m_{R}\right)}{\beta_{R U}}\right]=1-\alpha
$$

where, $\mathrm{mR}, \alpha$ is the fractile of the median given the confidence level $\alpha$, which can be further derived as:

$$
m_{R, \alpha}=m_{R} \exp \left[-\beta_{R U} \Phi^{-1}(\alpha)\right]=\left(\frac{m_{C}}{a}\right)^{\frac{1}{b}} \exp \left[-\beta_{R U} \Phi^{-1}(\alpha)\right]
$$

Then, the interval estimation of the fragility function becomes:

$$
F_{R}(x)=\Phi\left[\frac{\ln \left(x / m_{R}\right)}{\beta_{R}}\right]=\phi\left\{\frac{\ln x /\left(m_{C} / a\right)^{\frac{1}{b}} \exp \left[-\beta_{R U} \Phi^{-1}(\alpha)\right]}{\sqrt{\beta_{D \mid I M=x}^{2}+\beta_{C R}^{2}}}\right\}
$$

where the dispersion of the fragility $\square \mathrm{R}$ just represents the aleatory uncertainty of the fragility, which can be calculated by the first method mentioned above. The belief interval is assumed to have lower and higher bounds equal respectively to $16 \%$ and $84 \%$ :

$$
m_{R, 16 \%}(x)=m_{R R} \exp \left(-\beta_{U}\right), m_{R, 84 \%}(x)=m_{R R} \exp \left(\beta_{U}\right)
$$


Equation 10 shows clearly the process of the uncertainty propagation from the hazard, the fragility and the recovery functionality to the expected recovery functionality. The uncertainty in $\mathrm{Q}$ consists of corresponding to the uncertainty in $\mathrm{P}(\mathrm{IM}=\mathrm{i}), \mathrm{P}(\mathrm{DM}=\mathrm{j} \mid \mathrm{IM}=\mathrm{i})$ and $\mathrm{Qj}$. The functionality restoration of bridges is affected by a large amount of uncertainties associated with the condition of the disaster area, the decisions of disaster relief, the support from surrounding areas, etc. (Frangopol et al. 2011). Given that the related research regarding to this uncertainty is limited in the literature, additional research is needed to address this shortcoming. For the sake of brevity, the uncertainty associated to the Qj is here neglected in this content. It is assumed that all the uncertainty for the expected recovery functionality is derived from the occurrence of the earthquake and the damage. Then, the epistemic uncertainty in Q derived from decision making could be considered in the fragility analysis.

\section{DETERMINATION OF PULSE-LIKE GROUND MOTIONS}

It is well known that the near-fault (NF) earthquakes can induce significant seismic damages to the structures. The single or multiple pulses observed in their velocity time histories is the key characteristic for this type of ground motions. With respect to this feature, those ground motions can obviously induce higher seismic demands (Bertero et al. 1978; Hall et al. 1995; Chopra and Chintanapakdee 2001; Alavi and Krawinkler 2001, 2004). Consequently, it is strongly suggested to use this type of ground motions for the seismic assessment of bridges.

In the following, a method to quantify the strong velocity pulse that characterizes NF pulselike ground motions is introduced (Zhai et al. 2013). The least-square fitting (LSF) technique is firstly used to find best matching with the main velocity pulse of the real ground motion of a simplified numerical model of the time history. Then, the parameters of the velocity pulse (e.g., period of pulse, perk velocity) are identified by using the perk-point method (PPM). Finally, the energy index (Ep) is defined and calculated to determine, for the selected natural earthquake records, the pulse-like ground motions (Baker 2007; Zhai et al. 2013).

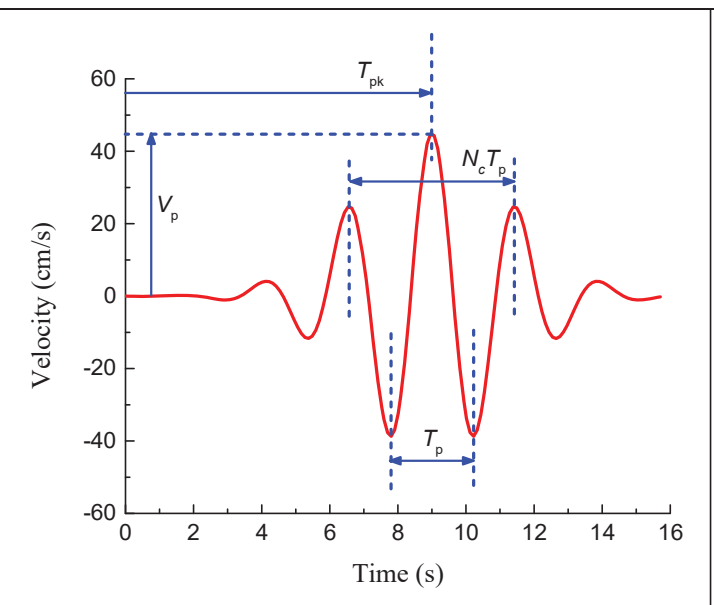

Fig.2. Mathematical model of velocity pulse for $=0$ (Dickinson \& Gavin 2011)

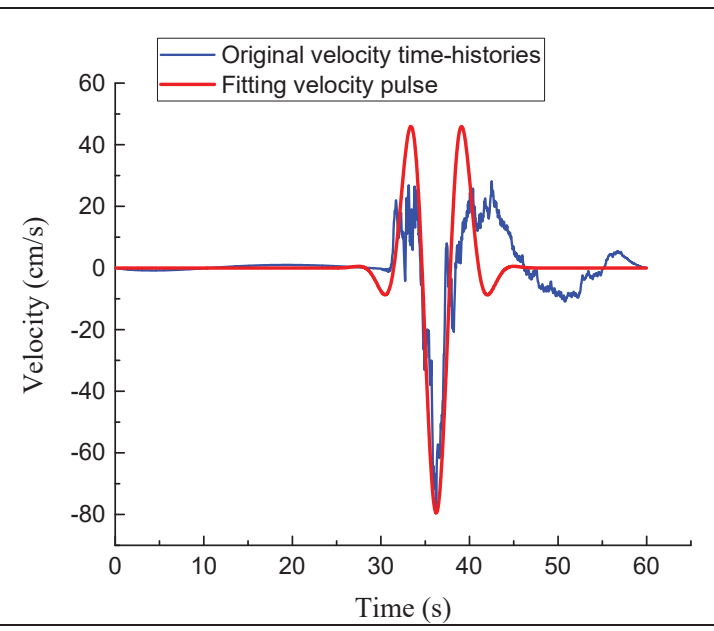

Fig.3. Illustration of PPM for NGA1171

As shown in Fig.2, the pulse model is defined as (Dickinson \& Gavin 2011):

$$
v_{p}\left(t ; V_{p}, T_{p}, N_{c}, T_{p k}, \varphi\right)=V_{p} \exp \left[-\frac{\pi^{2}}{4}\left(\frac{t-T_{p k}}{N_{c} T_{p}}\right)^{2}\right] \times \cos \left(2 \pi \frac{t-T_{p k}}{T_{p}}-\varphi\right)
$$

in which $v p$ is the velocity pulse, $\mathrm{Vp}$ and $\mathrm{Tp}$ are respectively the amplitude and the period of the pulse, Nc and Tpk represent the number of cycles and the location in the pulse time-history, 
and $\varphi$ is the phase of the pulse. The LSF algorithm is used to match the original velocity pulse and the simplified mathematical model, which is used to remove the high-frequency content of the real ground motions. Based on the PPM (Osaki 2008; Baker 2007), the perk velocity is extracted from the original velocity time histories to locate the velocity valley, and then the time interval of velocity valley is defined as the pulse period. Fig.3 illustrates the extracted velocity pulse for the NGA1171 ground motion.

With the aim to identify, among the selected natural records, the pulse-like ground motion, an energy-based method is used (Baker 2007). In this study, the determination indicator is defined as (Zhai et al. 2013):

$$
\left\{\begin{array}{c}
E_{p}=\int_{t_{s}}^{t_{e}} d E(t)=E\left(t_{e}\right)-E\left(t_{s}\right) \\
E(t)=\frac{\int_{0}^{t} v^{2}(\tau) d \tau}{\int_{0}^{\infty} v^{2}(\tau) d \tau}
\end{array}\right.
$$

in which Ep is the energy index, $\mathrm{E}(\mathrm{t})$ is the cumulative energy of the ground motion at time $t$, ts and te represent respectively the starting and ending time of the velocity pulse and $v(\tau)$ is the velocity time-history.

According to the recent studies (Zhai et al. 2013), the ground motions are determined as the pulse-like ground motions when the value of Ep is greater than 0.3. While the peak ground velocity is greater than $30 \mathrm{~cm} / \mathrm{s}$, the failure probability of this method is about $1.5 \%$. That means some non-pulse-like ground motions may be determined as the pulse-like ground motions. Since the number of the pulse-like ground motions is limited, this standard with value 0.3 is used.

\section{PROBABILISTIC RESILIENCE CALCULATION OF A SHORT-SPAN STEEL- CONCRETE COMPOSITE BRIDGE}

\subsection{Description of the bridge and its finite element model}

The case study is a typical short span overpass with two lanes, currently under investigation within the European Project SEQBRI (Paolacci et al. 2016). The bridge is $40.00 \mathrm{~m}$ long and consists of 2 spans of $20.00 \mathrm{~m}$ each.

The bridge presents two spans of $20.0 \mathrm{~m}$ each for a total length of $40.0 \mathrm{~m}$ (Fig. 4). The roadway width of bridge is $10.6 \mathrm{~m}$, including $6.5 \mathrm{~m}$ wide carriageway and two sidewalks of $2.05 \mathrm{~m}$ wide each. Four HE600B steel girders of S460 steel grade are used, with $2.65 \mathrm{~m}$ inbetween distance. The thickness of the concrete slab is $25 \mathrm{~cm}$. The steel girders are monolithically connected to the pier by a reinforced concrete crossbeam (CCB) $0.9 \mathrm{~m}$ wide, whereas they are simply supported on normal (low) damping bearings at the abutment through an additional CCB.

Details of the CCB configuration are shown in Fig. 5. The pier of wall type is $7.0 \mathrm{~m}$ height, $0.6 \mathrm{~m}$ thick and $7.0 \mathrm{~m}$ wide. The foundation soil is assumed to be categorized as type B according to EN1998 (BIBLIO) and the soil structure interaction effect is neglected. 


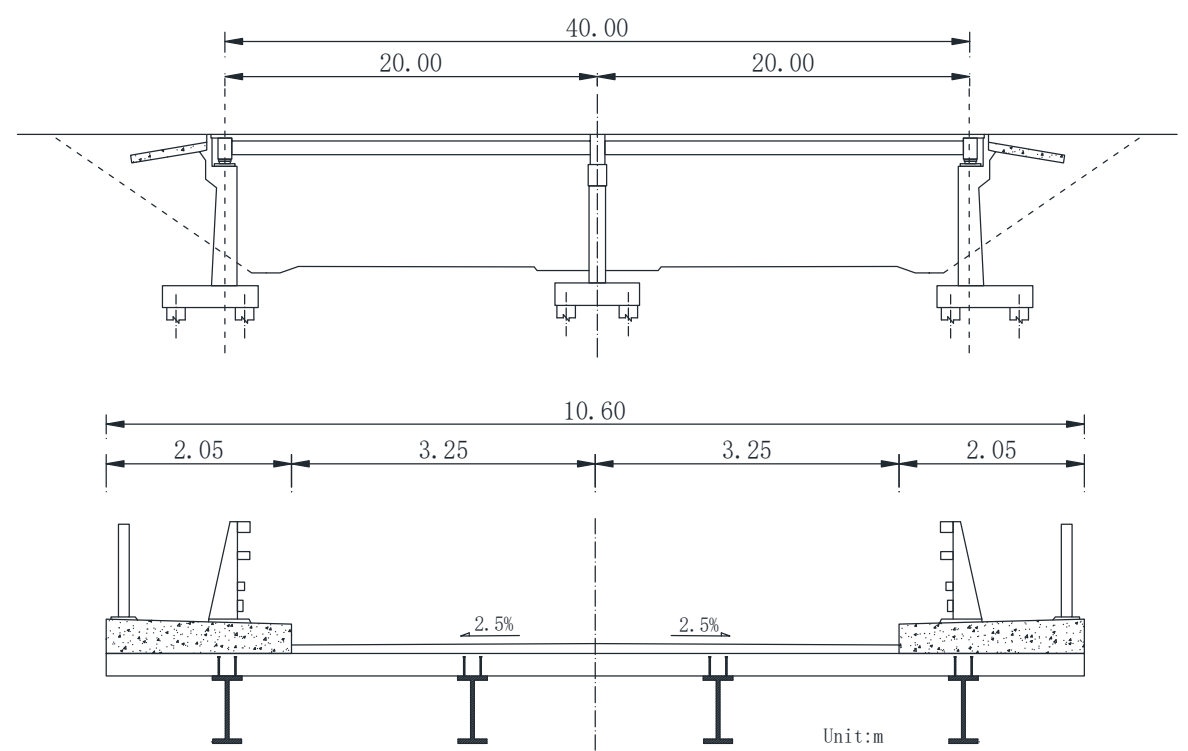

Fig. 4. Longitudinal section and cross section at span

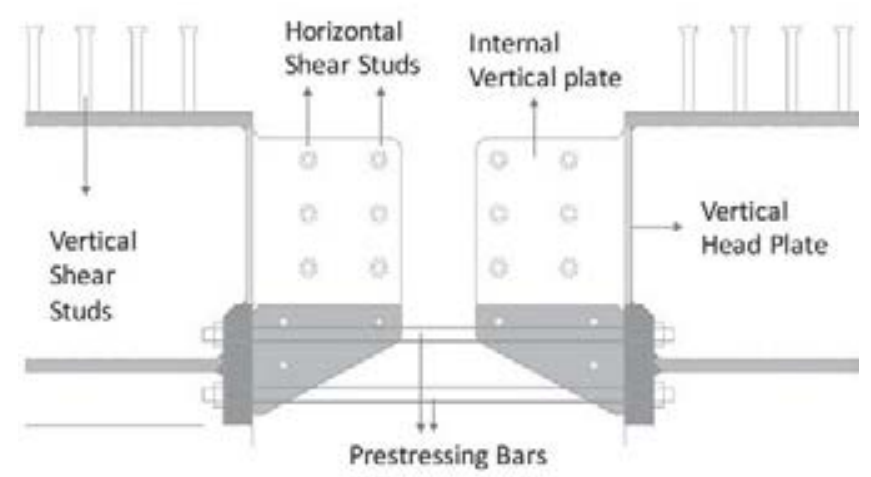

Fig. 5. CCB configuration

The 3D finite element (FE) model illustrated in Fig. 6 has been developed by using the OpenSees software (McKenna et al. 2007). In this model, the nonlinearities of materials are explicitly considered. In particular, the nonlinear beam elements with fiber cross-sections are used to model the single steel girder and the tributary concrete slab (Fig. 6 and 7). The Menegotto-Pinto model is adopted to simulate the mechanical behavior of steel girders and slab reinforcement, whereas the Kent and Park model is used to reproduce the mechanical behavior of concrete.

Nonlinear links with elasto-plastic behavior are used to model the vertical shear studs connecting the steel girders to the slab as well as the shear studs within the CCB. The strength of the shear studs has been evaluated in accordance with CEN (2006), while the stiffness has been evaluated by means of the load-slip curves experimentally defined by Gattesco and Giuriani (1996), even though different other recent proposal has been formulated (Shim et al. 2004; Lee et al. 2005).

Horizontal elasto-plastic links are also used to simulate the shear studs along the deck whereas the vertical direction and the rotation are constrained by rigid links between girders and slab. 


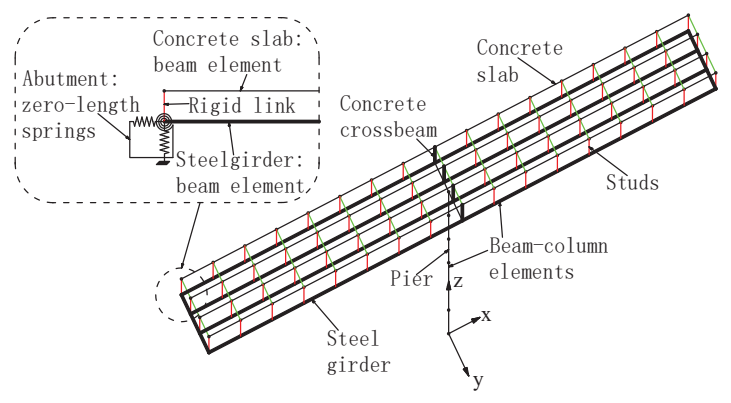

Fig. 6. 3-D finite element model

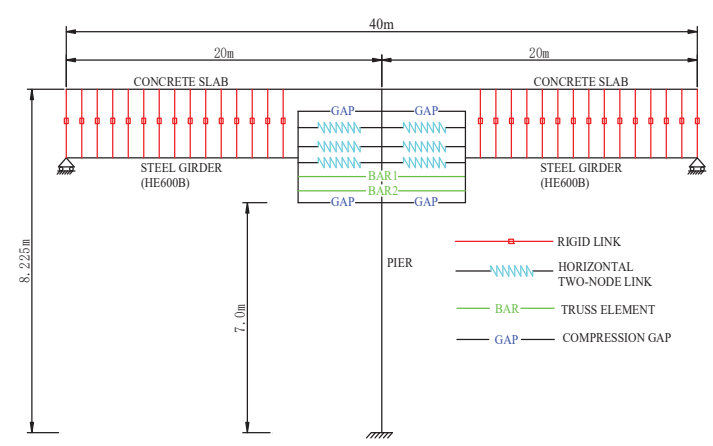

Fig. 8. 2D view of the model and details of the $\mathrm{CCB}$ modeling of the single composite beam

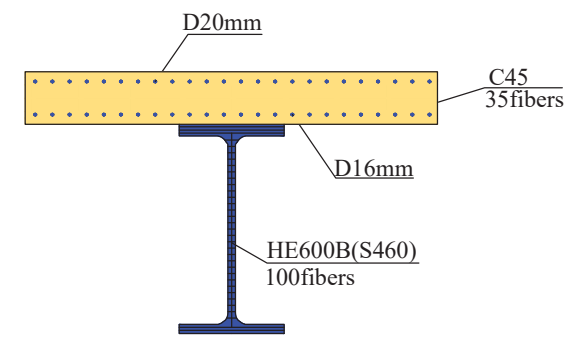

Fig. 7. Fiber sections of the single composite beam

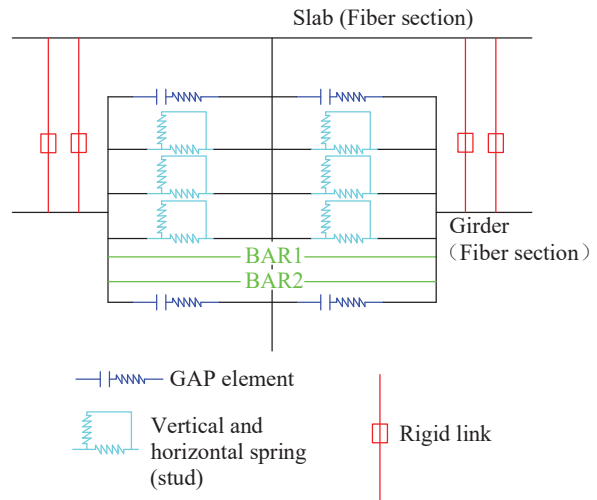

Fig. 9. 2D Component-based model of CCB joint

The behavior of the CCB joint is difficult to reproduce. For this reason, a component-based model has been recently proposed (Paolacci et al. 2014), which is currently under experimental investigation.

Rigid links are used to model the vertical head plates welded on the steel girders and directly in contact with the transverse concrete beam. Different non-linear links reproducing the behavior of the horizontal shear headed studs within the joint are connected to these rigid links according to the CCB configuration (Fig. 5). In order to reproduce the constraint in compression due to the presence of the $\mathrm{CCB}$, gap elements are adopted at both left and right sides of the CCB joint at two different heights, as shown in Fig. 8. A simplified evaluation of the stiffness of the gap elements is performed, assuming that the compressive force transmitted by the girder would act uniformly on the contact area of the vertical head plate. The two groups of prestressing bars at the bottom area of the CCB, are modeled by two elastic truss elements. The 2-D FE model for concrete cross beam is shown in detail in Fig. 9.

\subsection{Selection of input ground motions}

The case study is a typical short span overpass with two lanes, currently under investigation within the European Project SEQBRI (Paolacci et al. 2016). The bridge is $40.00 \mathrm{~m}$ long and consists of 2 spans of $20.00 \mathrm{~m}$ each.

Based on PEER strong ground motion database, a suite of ground motion records has been selected, which includes 60 near-fault (NF) pulse-like ground motions and 60 far-field (FF) ground motions. Two hazard conditions are adopted to select NF ground motions: moment magnitudes (MW) greater than 6.0 and site-to-source distances (R) less than $20 \mathrm{~km}$ (Stewart et 
al. 2002; Bary and Rodriguez-Marek 2004). Additionally, the dimensionalized peak ground velocity (PGV) and peak ground acceleration (PGA) were imposed to be greater than 0.2 (Kwon and Elnashai 2006; Padgett 2008; Zhai et al. 2012). The FF ground motion records were selected to match the PGA and MW of the NF records, but with $\mathrm{R}>20 \mathrm{~km}$. The selected NF ground motions were recorded during the following 5 strong earthquake events: Imperial Valley Earthquake (America, 1979), Palm Springs Earthquake (America, 1986), Northridge Earthquake (America, 1994), ChiChi Earthquake (Taiwan, 1999) and Kocaeli Earthquake (Turkey, 1999); the $80 \mathrm{FF}$ ground motions records belongs to the previous strong seismic events, with the addition of Whittier Narrows Earthquake (America, 1987) and Kobe Earthquake (Japan, 1995). Table 1 reports the selected NF ground motions.

Based on the identification approach described in section 3, all the NF ground motions have been identified as pulse-like ground motions. Due to the limited space, only their energy index Ep is shown in Fig. 10.

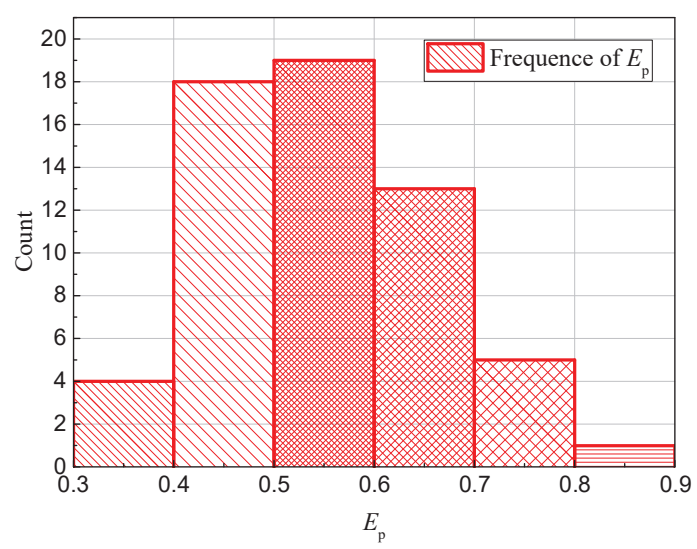

Fig. 10. Energy index Ep for NF ground motions selected

\subsection{Fragility analysis}

As stated before, the main damage is expected to be in the pier, which is the most vulnerable element of the bridge with potential catastrophic consequences. Usually piers experience different degrees of damaging, from the cover spalling of concrete to the buckling of longitudinal reinforcement or bar fracture. In what follows these three damage levels have been assumed as Damage Measures. Berry and Eberhard (2003), developed empirical equations to estimate deformations at the above damage levels calibrated with a series of existing experimental tests from the UW-PEER reinforced concrete column performance database, which include the performance of over 400 columns. Concrete cover spalling represents the initial damage state that may cause a possible short-term loss of functionality along with a significant repair cost. Bar buckling and fracture represent instead damage states in which safety implications are particularly important, which may imply partial replacement and a longer term loss of functionality. Concrete cover spalling, bar buckling and bar fracture can be defined as a moderate, extensive and complete damage condition. A closed-form of the median value of the drift $(\mathrm{mC})$ was proposed by Berry and Eberhard for damage estimation, which read: 


$$
\begin{array}{cc}
\frac{\Delta_{s p}^{c a l c}}{L}(\%)=1.6\left(1-\frac{P}{A_{g} f_{c}^{\prime}}\right)\left(1+\frac{L}{10 D_{e}}\right) & \begin{array}{c}
\text { Concrete cover } \\
\text { spalling }
\end{array} \\
\frac{\Delta_{b b}^{\text {calc }}}{L}(\%)=3.25\left(1+k_{e} \rho_{\text {eff }} \frac{d_{b}}{D_{e}}\right)\left(1-\frac{P}{A_{g} f_{c}^{\prime}}\right)\left(1+\frac{L}{10 D_{e}}\right) & \text { Bar buckling } \\
\frac{\Delta_{b f}^{\text {calc }}}{L}(\%)=3.25\left(1+k_{e} \rho_{\text {eff }} \frac{d_{b}}{D_{e}}\right)\left(1-\frac{P}{A_{g} f_{c}^{\prime}}\right)\left(1+\frac{L}{10 D_{e}}\right) & \text { Bar fracture }
\end{array}
$$

where $\mathrm{ke}=40, \rho \mathrm{eff}=0.307$ volumetric transverse reinforcement ratio, f'c concrete compressive strength, db diameter of the longitudinal reinforcement, De column depth, $\mathrm{P}$ axial load at the column base, Ag gross area of the cross-section and L distance from the column base to the point of contra flexure. An alternative representation of the damage condition in the pier is the plastic deformation at bottom section. The corresponding levels of damage, obtained in the pier, are for concrete cover spalling $1.37 \%$, for buckling $4.25 \%$ and for fracture $8.96 \%$.

According to the HAZUS99 (1999), the damage indices represented the damage of bridge piers are defined as the ductility ratio. Using the case data, the damage indices are calculated and converted to the drift ratio. The results are $0.63 \%$ for slight damage, $1.31 \%$ for moderate damage, $4.31 \%$ for extensive damage and $12.3 \%$ for complete damage. Compared to the results of Berry and Eberhard method, the values of damage indices for moderate damage and extensive damage are close. The usefulness of this method is manifested. For the experimental results which are generally considered being more reliable, the results of Berry and Eberhard method for moderate, extensive and complete damage are defined as the main damage indices while the slight damage index of the HAZUS results is the supplement. The comprehensive damage index of the pier is listed in Table 3.

Table 3. Damage index for pier drift ratio

\begin{tabular}{lcccc}
\hline & $\begin{array}{c}\text { Slight } \\
\text { damage }\end{array}$ & $\begin{array}{c}\text { Moderate } \\
\text { damage }\end{array}$ & $\begin{array}{c}\text { Extensive } \\
\text { damage }\end{array}$ & $\begin{array}{c}\text { Complete } \\
\text { damage }\end{array}$ \\
\hline $\begin{array}{l}\text { Damage index } \\
\text { (Drift ratio) }\end{array}$ & $0.63 \%$ & $1.37 \%$ & $4.25 \%$ & $8.96 \%$ \\
\hline
\end{tabular}

Concerning the aleatory uncertainties considered in fragility analysis, the dispersion of capacity fragility $\square \mathrm{C}$ is assumed equal to 0.3 based on the experimental data elaborated by Berry and Eberhard (2003). In Fig. 11 the seismic fragility curves with intensity measures Sa are shown; it is evident that the POE of any level of damage in the pier is larger for the NF pulselike ground motions. In fact, in the considered range of the IMs, the maximum probability of exceeding bars buckling in the NF region is about $90 \%$, while in FF region is about $60 \%$; the probability of bars fracture is about $30 \%$ under NF pulse-like ground motions and only $5 \%$ in the FF region. 


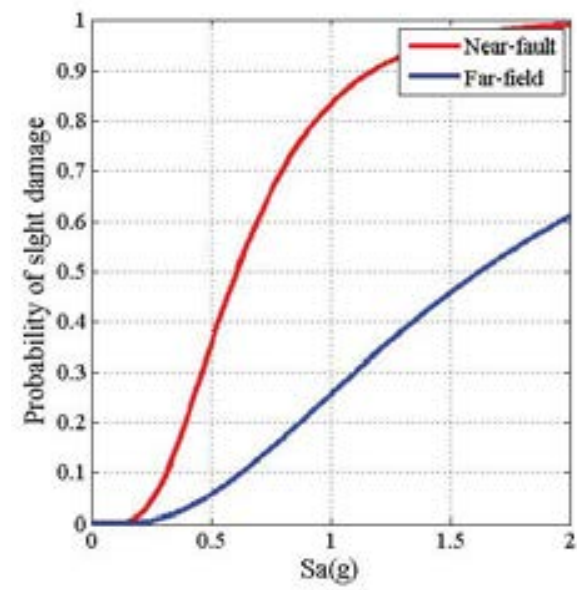

(a)

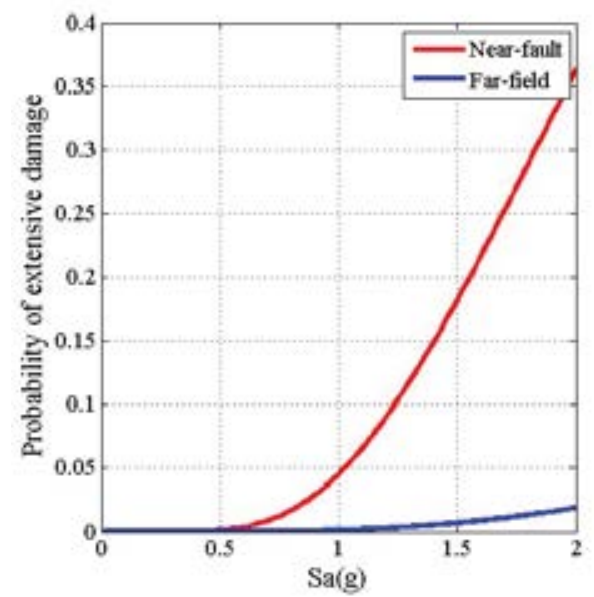

(c)

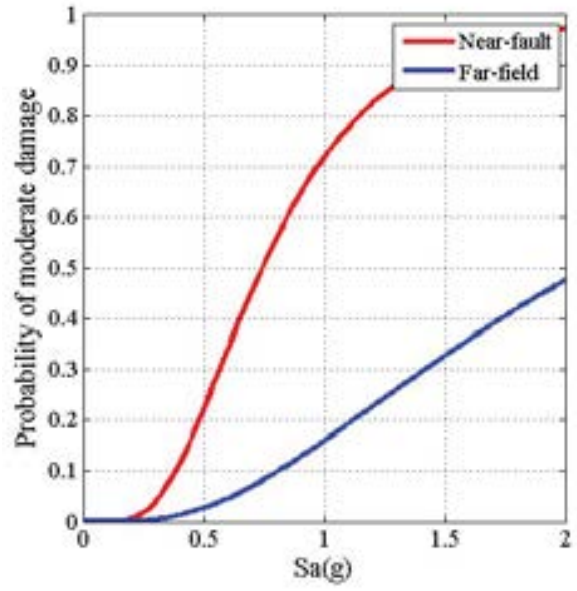

(b)

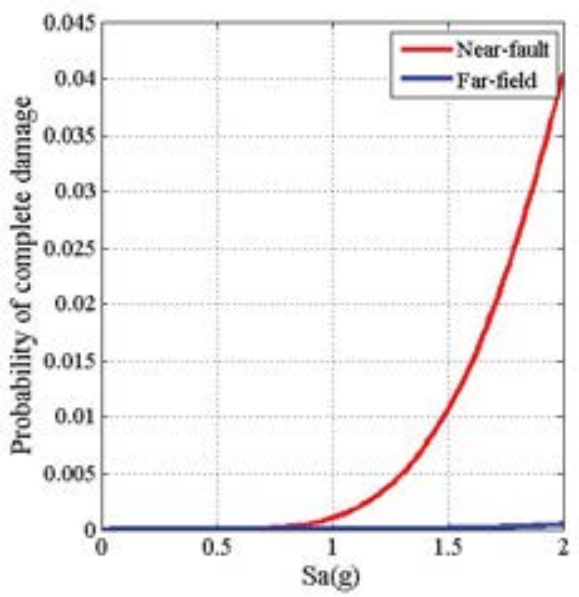

(d)

Fig. 11. Comparison of fragility curves of piers with the given IMs on longitude: (a) slight damage, (b) moderate damage, (c) extensive damage, and (d) complete damage

In contrast to aleatory uncertainties, which are essentially irreducible, the epistemic uncertainties generally can be reduced through additional knowledge provided at the expense of more comprehensive (and costly) data acquisition and analysis. Existing studies indicated that the dispersion of fragility in terms of epistemic uncertainties can be assumed as 0.2 (Ellingwood et al. 2009; Haleem et al. 2010).

With the point estimation and interval estimation method mentioned in section 2.4, the fragility curves for near-fault earthquakes considering both aleatory and epistemic have been developed. They are illustrated in Fig. 12. The epistemic uncertainties are labelled as EU. The bounds of the belief interval is assumed to $16 \%$ and $84 \%$.

Considering the epistemic uncertainty discussed in Section 2.4, seismic fragility curves with point estimation and interval estimation have been developed. Fig. 12 depicts fragility curves for each limit state. For slight damage and moderate damage, the probability considering epistemic uncertainties is similar to the probability with only aleatory uncertainties, and the epistemic uncertainty can be neglected. But the probability with EU is always bigger than the probability without EU in the considered range of IM. So it is meaningful to consider the 
epistemic uncertainty for fragility estimation when the bridges face to extreme events, which can in-duce the extensive damage and complete damage.

It is easy to see that the interval of probability estimation is increasing with the damage. A possible reason is that the epistemic uncertainties reduce the accuracy of probabilistic models for the heavy damage states.

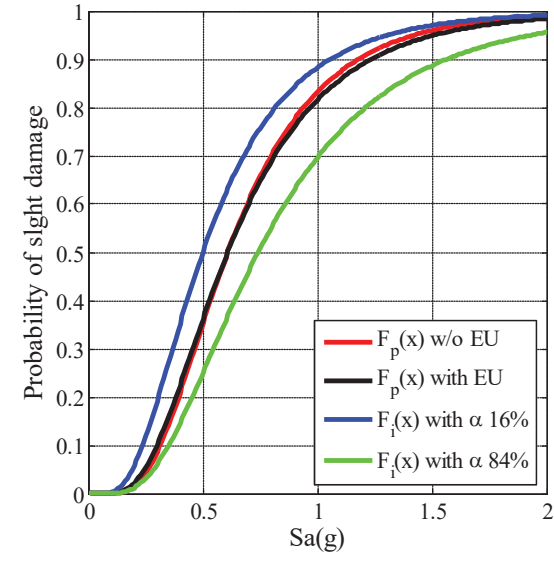

(a)

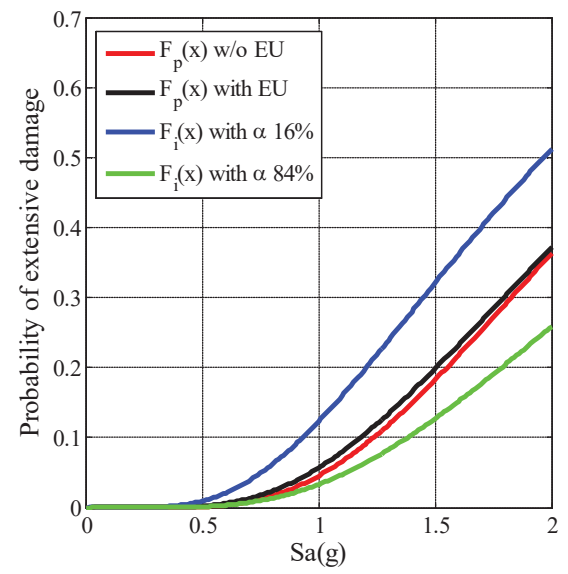

(c)

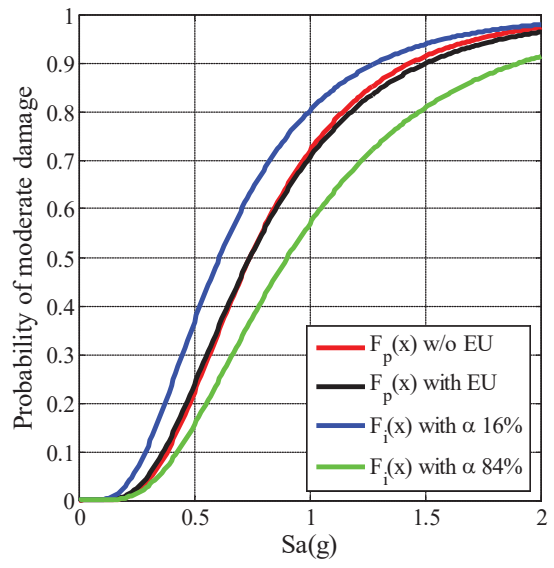

(b)

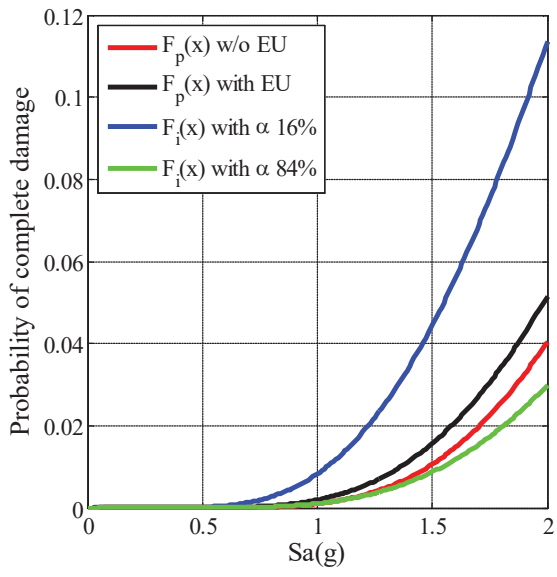

(d)

Fig. 12. Point and interval estimate for near-fault earthquake fragility curves considering epistemic uncertainty: (a) slight damage, (b) moderate damage, (c) extensive damage, and (d) complete damage

\subsection{Probabilistic Resilience estimation}

System and component level fragility curves have been shown in the previous section. Based on these data, the seismic resilience analysis of the selected case study has been performed following the method presented in Section 2.3. The bridge is assumed to be located in Los Angeles, California, USA, whose hazard curves, for a reference life of 100 years, has been provided by the the United States Geological Survey (USGS).

Considering the scarcity of statistical data concerning loss and post-earthquake recovery for bridges, in this work the loss estimation for highway bridges in California (ATC-13, 1985) has been used. In particular, the functionality recovery functions proposed by expertise-based surveys have been adapted for seismic resilience estimation. The selected recovery function is 
specific for steel-concrete composite highway bridges, whose functionality is defined as the traffic capacity and the category is $25 \mathrm{c}$.

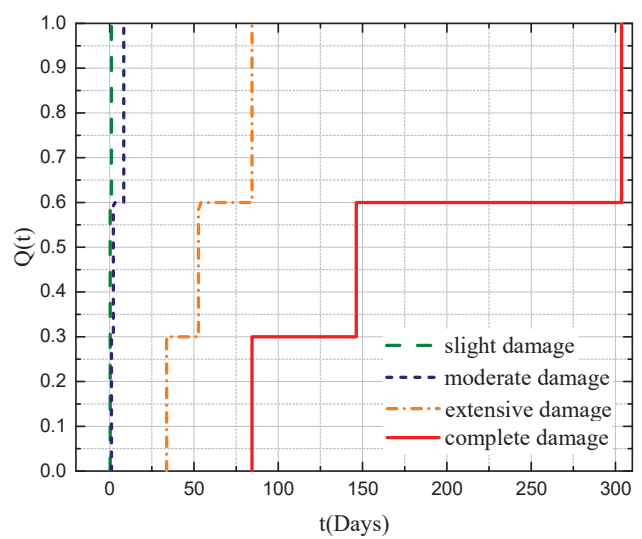

Fig. 13. Functionality recovery profiles from ATC-13

The recovery profiles of the function are listed in tabular form and present the mean time required to recover specific percentage $(30 \%, 60 \%, 100 \%)$ of normal functionality. For the present study, referring to the damage definition provided by ATC-13, the damage states 2 through 5 are assumed to be the corresponding damage states from slight to complete damage. The selected recovery function is presented in Fig.13.

According to ATC-13, the time horizon investigated for the functionality recovery function from is 303.6 days. Consequently, the time horizon of the expected functionality restoration is limited to maximum of 303.6 days by using Equation (7).

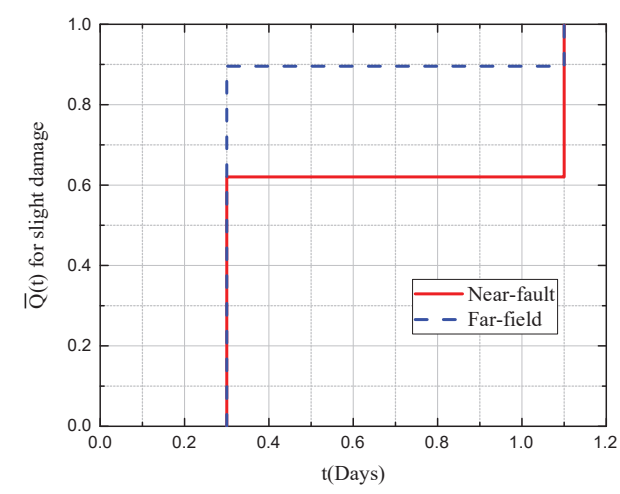

(a)

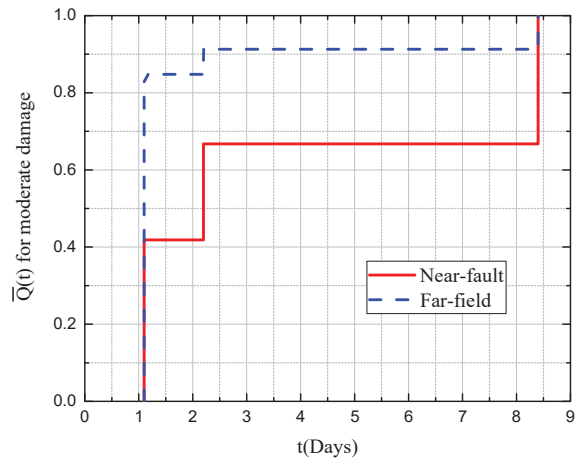

(b)

Fig. 14. Expected functionality recovery of bridge at different damage levels: (a) slight damage, (b)moderate damage, (c)extensive damage, and (d)complete damage

Fig. 14 illustrates the expected functionality recovery processes of the bridge for each damage state. Two recovery profiles are presented in the figures both for near-fault and far-field earthquakes. The expected functionality recovery of the whole bridge is instead shown in Fig. 15. Assuming that the total recovery time is constant and the initial damage is null, the obtained functionality paths appears rather different. It can be easily seen that the damage caused by 
near-fault earthquakes is more hard to be recovered. In other words, the seismic resilience demand of the bridge struck by near-fault earthquakes is larger than resilience demands coming from far-field earthquakes.

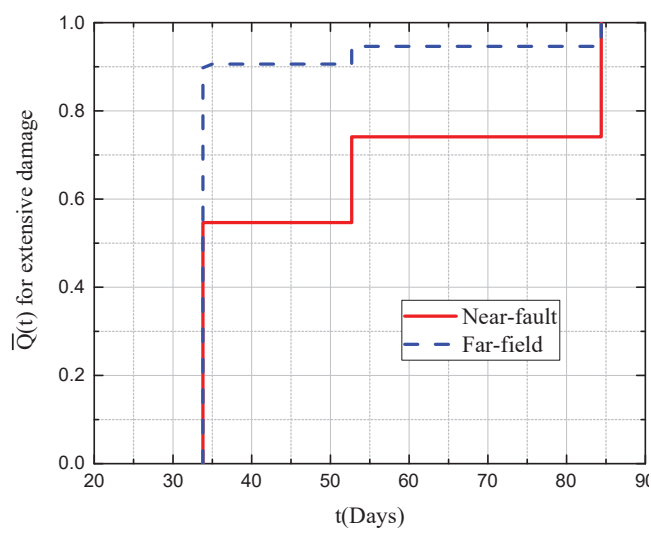

(c)

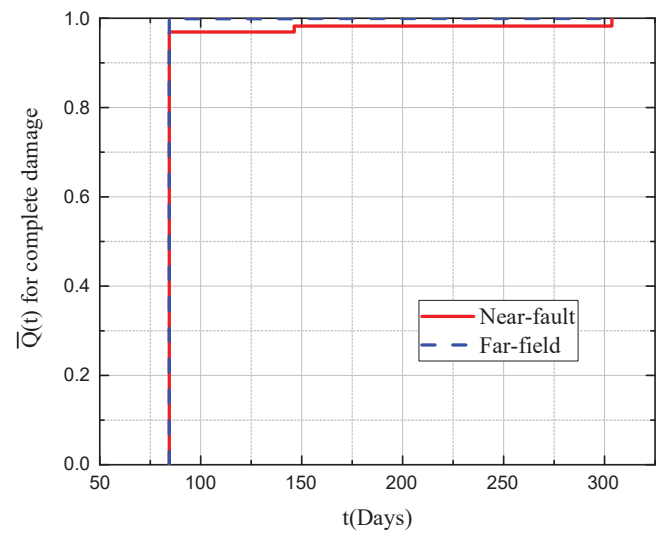

(d)

Fig. 14. Expected functionality recovery of bridge at different damage levels: (a) slight damage, (b)moderate damage, (c)extensive damage, and (d)complete damage

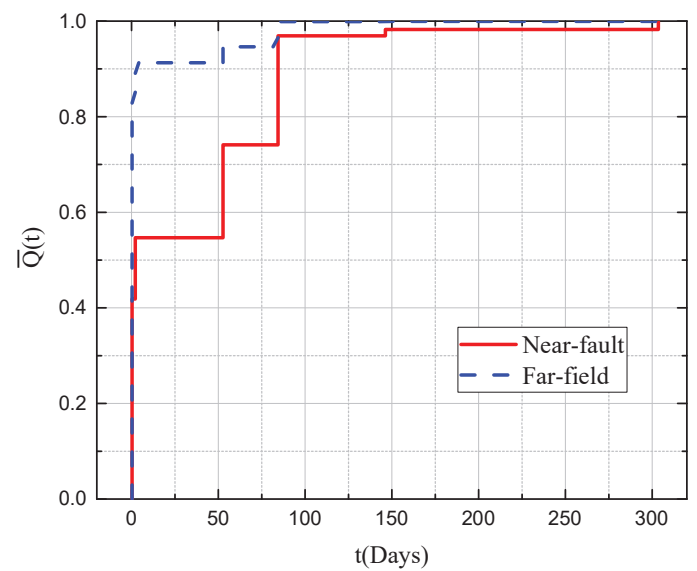

Fig. 15. Expected functionality recovery of whole bridge

Using the fragility curves with epistemic uncertainties (Fig. 16 and 17), the expected functionality recovery estimation can be developed also by using Equation (10). The interval estimation of recovery curves presents a variation tendency similar to fragility curves, which is more uncertain for higher damage. As shown in Fig. 15, it is easy to find that the interval estimation width is broaden for increasing recovery time. This is caused by the increasing of epistemic uncertainty with damage states and the variation of recovery service. 


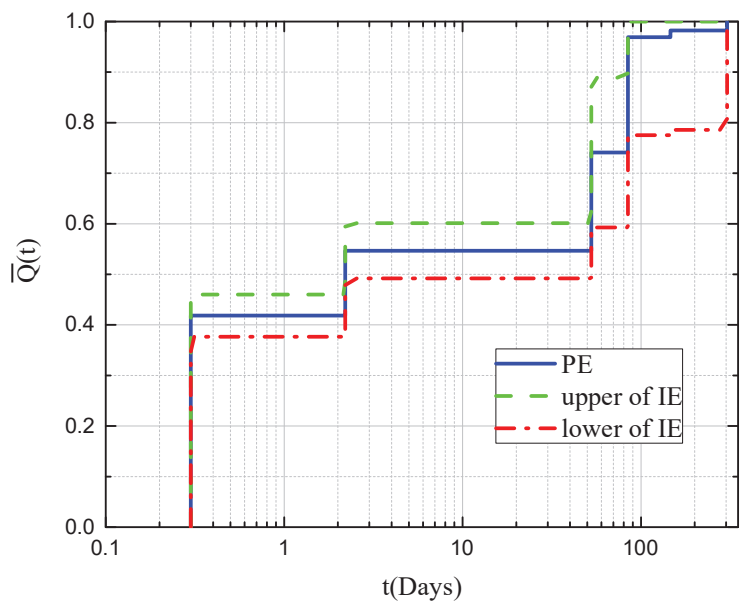

Fig.17. Interval estimation and point estimation of expected functionality recovery for whole bridge

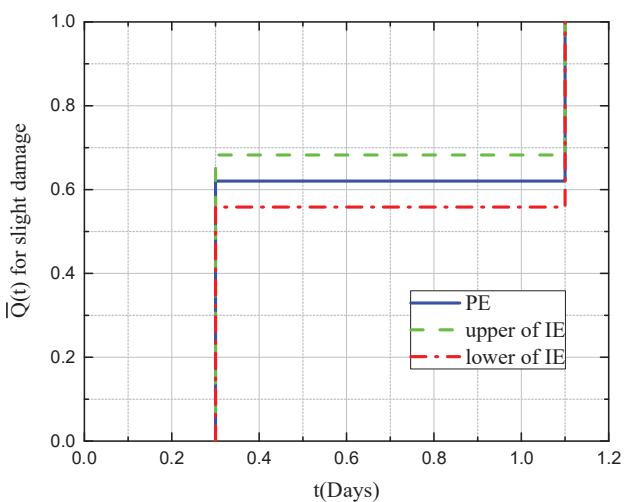

(a)

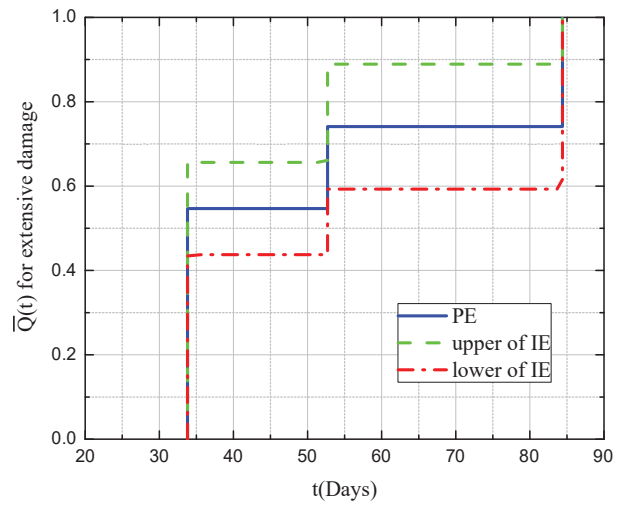

(c)

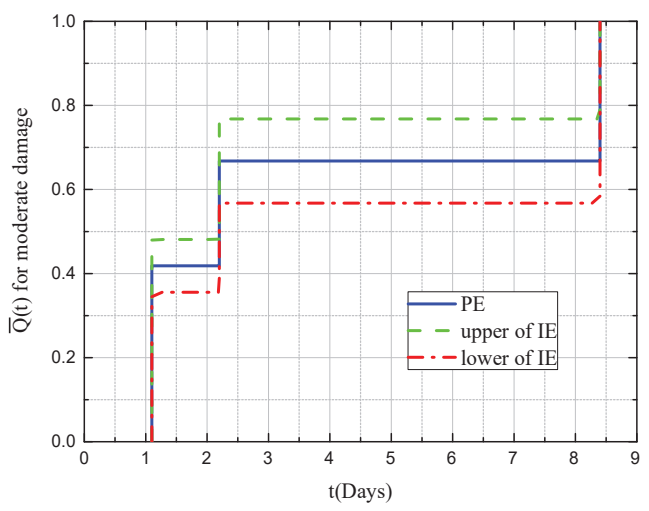

(b)

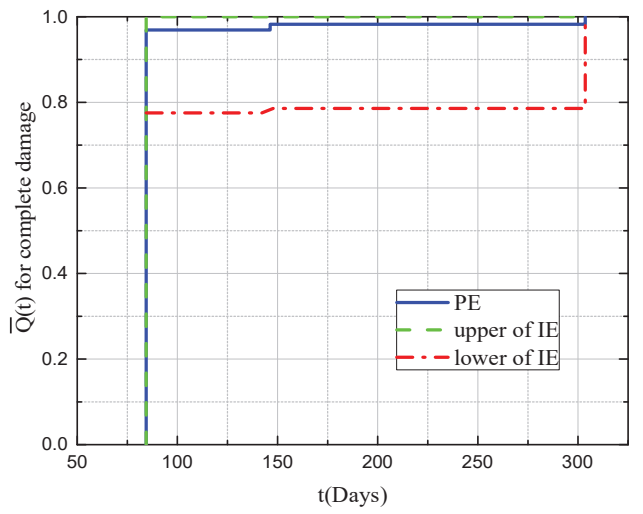

(d)

Fig. 16. Point estimation and interval estimation of expected functionality recovery at different damage levels: (a)slight damage, (b)moderate damage, (c)extensive damage, and (d)complete damage

The resilience of the bridge can be determined using Equation (9). The resilience index is shown in Table 4. It can be found that the resilience of the bridge struck by far-field earthquakes 
$(0.98)$ is larger than that under near-fault earthquakes $(0.89)$. The horizon of resilience interval estimation for this type of bridges under the near-fault earthquakes ranges from 0.91 to 0.86 .

Table 4. The expected resilience index of bridge

\begin{tabular}{lcc}
\hline & $\begin{array}{l}\text { Near- } \\
\text { fault }\end{array}$ & Far-field \\
\hline $\begin{array}{l}\text { Expected resilience index } \\
\begin{array}{l}\text { Upper of interval } \\
\text { estimation }\end{array}\end{array}$ & 0.89 & 0.98 \\
$\begin{array}{l}\text { Lower of interval } \\
\text { estimation }\end{array}$ & 0.91 & - \\
\hline
\end{tabular}

\section{CONCLUSIONS}

The probabilistic seismic resilience of steel concrete composite bridges with concrete cross beams is estimated by a simulation approach and the resilience demand after the near-fault earthquake events is quantified. The following conclusions are obtained:

1. The assessment process of seismic resilience is performed in a probabilistic way by using the seismic fragility analysis and considering both aleatory and epistemic uncertainties derived respectively from earthquakes and the structure.

2. It has been found that the uncertainties of the restoration path increase along the time and when more severe damage occurs.

3. The near-fault pulse-like earthquakes have significant effects on the seismic performance of the bridge. The result have shown that the estimation resilience of the bridge under NF earthquakes is about $10 \%$ less than $\mathrm{FF}$ earthquakes; the function restoration indicates that the bridge under NF earthquakes is more difficult to recover than that under FF earthquakes.

4. It has been demonstrated that the simplified approach proposed in this paper can be profitably used to approximately and easily estimate the seismic resilience of a steel concrete composite bridge. This suggests further developments devoted to the extension of the method for the calculation of the resilience of bridge network systems.

It has been found that the main barrier for the seismic resilience assessment is limited by the scarce number of studies investigating the functionality recovery functions. In this respect, current on-going research activities concerning this aspect will lead to better restoration process models, which it will increase the assessment accuracy..

\section{AKNOWLEDGMENTS}

The authors would like to thank the Editor and the anonymous reviewers for their constructive comments and valuable suggestions to improve the quality of the article. The financial supports received from the National Science Foundation of China (Grant Nos. 51378162, 51908384), and the China Postdoctoral Science Foundation (2020M673223) is gratefully appreciated. The present work is also supported by the funds of the European Project SEQBRI: "Performance-Based Earthquake Engineering Analysis of Short-Medium Span Steel-Concrete Composite Bridges", Grant N RFSR-CT-2012-00032. 


\section{REFERENCES}

[1] Alavi B, Krawinkler H (2001) Effects of near-fault ground motions on frame structures. Technical Report, Blume Center Report 138, Stanford, California

[2] Alavi B, Krawinkler H (2004) Behavior of moment-resisting frame structures subjected to near-fault ground motions. Earthquake engineering \& structural dynamics 33, 687-706

[3] ATC (1985) Earthquake damage evaluation data for California. Technical Report ATC13, Applied Technology Council (ATC), Redwood City, CA

[4] Baker JW (2007) Quantitative classification of near-fault ground motions with wavelet analysis. Bulletin of the Seismological Society of America 97(5): 1486-1501

[5] Bazzurro P (1998) Probabilistic Seismic Demand Analysis. PhD Dissertation. Stanford University: UMI

[6] Berry MP, Eberhard M (2003) Performance Models for Flexural Damage in Reinforced Concrete Columns. PEER Report, 2003/18

[7] Bertero VV, Mahin SA, Herrera RA (1978) Aseismic design implications of near - fault San Fernando earthquake records. Earthquake engineering \& structural dynamics 6(1): $31-42$

[8] Bray JD, Rodriguez-Marek A (2004) Characterization of forward-directivity ground motions in the near-fault region. Soil dynamics and earthquake engineering 24(11): 815-828

[9] Bruneau M, Chang SE, Eguchi RT, Lee GC, O'Rourke TD, Reinhorn AM, Shinozuka M, Tierney K, Wallace AW, von Winterfeldt D (2003) A framework to quantitatively assess and enhance the seismic resilience of communities. Earthquake Spectra 19(4):733-752

[10] CEN (European Committee for Standardization) (2004) Design of composite Steel and Concrete Structures. Eurocode 4, Brussels

[11] Chopra AK, Chintanapakdee C (2001) Comparing response of SDF systems to near-fault and far-fault earthquake motions in the context of spectral regions. Earthquake Engineering \& Structural Dynamics 30(12): 1769-1789

[12] Cimellaro GP, Reinhorn AM, Bruneau M. (2010) Seismic resilience of a hospital system. Structure and Infrastructure Engineering 6(1-2):127-144

[13] Cornell CA (1968) Engineering seismic risk analysis. Bulletin of the Seismological Society of America 58(5): 1583-1606

[14] Cornell CA, Jalayer F, Hamburger RO, Foutch DA (2002) Probabilistic basis for 2000 SAC federal emergency management agency steel moment frame guidelines. Journal of Structural Engineering 128(4): 526-533

[15] Decò A, Bocchini P, Frangopol DM (2013) A probabilistic approach for the prediction of seismic resilience of bridges. Earthquake Engineering \& Structural Dynamics 42(10): $1469-1487$

[16] Dickinson BW, Gavin HP (2011) Parametric statistical generalization of uniform hazard earthquake ground motions. Journal of Structural Engineering(ASCE) 137(3): 410-422

[17] Ellingwood BR (2001) Earthquake risk assessment of building structures. Reliability Engineering \& System Safety 74(3): 251-262 
[18] Ellingwood BR, Kinali K. (2009). Quantifying and communicating uncertainty in seismic risk assessment. Structural Safety 31(2): 179-187

[19] Federal Emergency Management Agency (FEMA) (2006) Next-generation performancebased seismic design guidelines. Technical Report FEMA-445, Washington, D.C.

[20] Frangopol DM, Bocchini P (2011) Resilience as optimization criterion for the rehabilitation of bridges belonging to a transportation network subject to earthquake. Proceedings of the ASCE 2011 Structures Congress SEI 2011, Ames D, Droessler TL, Hoit M (eds). Las Vegas, NV; 2044-2055.

[21] Gardoni P, Der-Kiureghian A, Mosalam KM (2002) Probabilistic capacity models and fragility estimates for reinforced concrete columns based on experimental observations. Journal of Engineering Mechanics 128(10): 1024-1038

[22] Gattesco N, Giuriani E (1996) Experimental study on stud shear connectors subjected to cyclic loading. Journal of Constructional Steel Research 38(1): 1-21

[23] Haleem K, Abdel-Aty M, Mackie K (2010) Using a reliability process to reduce uncertainty in predicting crashes at unsignalized intersections. Accident Analysis \& Prevention 42(2): 654-666

[24] Hall JF, Heaton TH, Halling MW, et al (1995) Near-source ground motion and its effects on flexible buildings. Earthquake spectra 11(4): 569-605

[25] Federal Emergency Management Agency (FEMA) (1999) Earthquake loss estimation methodology: User's Manual. HAZUS99, Washington D.C.

[26] Karamlou A, Bocchini P (2015) Computation of bridge seismic fragility by large-scale simulation for probabilistic resilience analysis. Earthquake Engineering \& Structural Dynamics 44(12): 1959-1978

[27] Kwon OS, Elnashai A (2006) The effect of material and ground motion uncertainty on the seismic vulnerability curves of RC structure. Engineering structures 28(2): 289-303

[28] Lee PG, Shim CS, Chang SP (2005) Static and fatigue behavior of large stud shear connectors for steel-concrete composite bridges. Journal of Constructional Steel Research 61(9):12, 70-85

[29] Liu Y, Lu DG, Paolacci F (2015) Multivariate probabilistic seismic demand analysis of steel-concrete composite Bridges under Near-fault Pulse-like Ground Motions. Multispan large bridges, Portugal

[30] Lu DG, Yu XH, Jia MM, et al (2014) Seismic risk assessment for a reinforced concrete frame designed according to Chinese codes. Structure and Infrastructure Engineering 10(10): 1295-1310

[31] McKenna F, Mazzoni S, Scott MH, Fenves GL (2007) OpenSees command language manual. Pacific Earthquake Engineering Research Center, University of California, Berkeley, July

[32] Melchers RE (1999) Structural reliability: Analysis and prediction (2nd Ed.). Wiley, New York

[33] Osaki Y (2008) Spectral analysis in earthquake engineering. Seismological Press, Beijing

[34] Padgett JE, Des-Roches R (2007) Sensitivity of seismic response and fragility to parameter uncertainty. Journal of Structural Engineering 133(12): 1710-1718 
[35] Padgett JE (2008) Selection of optimal intensity measures in probabilistic seismic demand models of highway bridge portfolios. Earthquake Engineering and Structural Dynamics 37:711-725

[36] Paolacci F, Giannini R (2014) Toward a performance-based earthquake engineering analysis of short-medium span steel-concrete composite bridges. Second European Conference on Earthquake Engineering and Seismology. Istanbul

[37] Paolacci F, et al (2016) Performance-based earthquake engineering analysis of short-medium span steel-concrete composite bridges (SEQBRI), European research fund for coal and steel (RFCS). Grant N ${ }^{\circ}$ RFSR-CT-2012-00032, 2012-2015, Final Report, March 2016

[38] Shim CS, Lee PG, Yoon TY (2004) Static behavior of large stud shear connectors. Engineering Structures 26:18, 53-60

[39] Shome N (1999) Probabilistic Seismic Demand Analysis of Non-linear Structures. PhD Dissertation, Stanford University

[40] Stewart JP, Chiou SJ, Bray JD, et al (2002) Ground motion evaluation procedures for performance-based design. Soil dynamics and earthquake engineering 22(9): 765-772

[41] Tondini N, Stojadinovic B (2012) Probabilistic seismic demand model for curved reinforced concrete bridges. Bulletin of Earthquake Engineering 10: 1455-1479

[42] U.S. geological hazard science center (2012) http://geohazards.usgs.gov/hazardtool/application.php. Accessed 15 September 013

[43] Wen YK, Ellingwood BR, Veneziano D, et al (2003) Uncertainty modeling in earthquake engineering. MAE center project FD-2 report

[44] Xu N, Guikema SD, Davidson RA, Nozick LK, Çağnan Z, Vaziri K (2007) Optimizing scheduling of post-earthquake electric power restoration tasks. Earthquake Engineering and Structural Dynamics 36(2): 265-284

[45] Zhai C, Chang Z, Li S, Chen ZQ, Xie L (2013) Quantitative identification of near-fault pulse-like ground motions based on energy. Bulletin of the Seismological Society of America 103(5): 2591-2603. 